\title{
Risk of fractures with inhaled corticosteroids in COPD: systematic review and meta-analysis of randomised controlled trials and observational studies
}

\author{
Yoon K Loke, ${ }^{1}$ Rodrigo Cavallazzi, ${ }^{2}$ Sonal Singh ${ }^{3}$
}

- Additional materials are published online only. To view these files please visit the journal online (http://thorax.bmj. com).

${ }^{1}$ School of Medicine, University of East Anglia, Norwich, UK ${ }^{2}$ Department of Medicine Division of Pulmonary, Critical Care and Sleep Disorders Medicine, University of Louisville, Kentucky, USA ${ }^{3}$ Department of Medicine, Johns Hopkins University School of Medicine, Baltimore, Maryland, USA

\section{Correspondence to} Yoon K Loke, School of Medicine, University of East Anglia, Norwich NR4 7TJ, UK; y.loke@uea.ac.uk

Received 24 January 2011 Accepted 28 April 2011

Published Online First 20 May 2011
ABSTRACT

Background The effect of inhaled corticosteroids (ICS) on fracture risk in patients with chronic obstructive pulmonary disease (COPD) remains uncertain. The aim of this study was to evaluate the association between ICS and fractures in COPD.

Methods MEDLINE, EMBASE, regulatory documents and company registries were searched up to August 2010. Randomised controlled trials (RCTs) of budesonide or fluticasone versus control treatment for COPD ( $\geq 24$ weeks duration) and controlled observational studies reporting on fracture risk with ICS exposure vs no exposure in COPD were included. Peto OR meta-analysis was used for fracture risk from RCTs while ORs from observational studies were pooled using the fixed effect inverse variance method. Dose-response analysis was conducted using varianceweighted least squares regression in the observational studies. Heterogeneity was assessed using the $\mathrm{I}^{2}$ statistic.

Results Sixteen RCTs (14 fluticasone, 2 budesonide) with 17513 participants, and seven observational studies ( $n=69000$ participants) were included in the meta-analysis. ICSs were associated with a significantly increased risk of fractures (Peto OR 1.27; 95\% Cl 1.01 to 1.58; $p=0.04 ; l^{2}=0 \%$ ) in the RCTs. In the observational studies, ICS exposure was associated with a significantly increased risk of fractures (OR 1.21; $95 \% \mathrm{Cl} 1.12$ to 1.32; $p<0.001 ; r^{2}=37 \%$ ), with each $500 \mu$ increase in beclomethasone dose equivalents associated with a $9 \%$ increased risk of fractures, OR 1.09 (95\% Cl 1.06 to 1.12; $\mathrm{p}<0.001)$.

Conclusion Among patients with COPD, long-term exposure to fluticasone and budesonide is consistently associated with a modest but statistically significant increased likelihood of fractures.

\section{BACKGROUND}

The inhaled corticosteroids (ICS) fluticasone propionate and budesonide are widely used in the treatment of chronic obstructive pulmonary disease (COPD). ${ }^{1}$ The Global Initiative for Chronic Obstructive Lung Disease guidelines recommend ICS in combination with long-acting $\beta_{2}$-agonists (LABAs) in moderate to severe COPD to reduce the frequency of exacerbations, ${ }^{2}$ and current formulations of ICS approved for use in COPD are fluticasone with salmeterol, and budesonide with formoterol. The potential benefits of ICS are counterbalanced by their systemic adverse effects such as pneumonia and their potential to negatively impact bone health. ${ }^{3} 4$

\section{Key messages}

What is the key question?

- Does long-term use of inhaled corticosteroids increase the risk of fractures in patients with chronic obstructive pulmonary disease (COPD)?

What is the bottom line?

- Our meta-analysis shows that inhaled corticosteroid use is associated with a modest but statistically significant increase in the risk of fractures in patients with COPD.

\section{Why read on?}

- The consistency and similarity of the point estimates across randomised trials and observational study designs, and the presence of a dose-response effect in the observational studies lends credibility to this clinically important association.

Prior evidence on the adverse skeletal effects of ICS has been inconsistent. Published evaluations of bone mineral density (BMD) with ICS exposure are limited by considerable losses to follow-up in three large randomised controlled trials (RCTs), with bone density data available only in selected participants. ${ }^{5-7}$ Two trials (one fluticasone, one budesonide) reported no significant adverse effect on $\mathrm{BMD}$, perhaps due to inadequate statistical power. ${ }^{5} 6$ In the Towards a Revolution in COPD Health (TORCH) subset, patients on salmeterol had a small gain in spine $\mathrm{BMD}$, as compared with patients receiving salmeterol/fluticasone in combination who had a marginal decrease. ${ }^{5} \mathrm{BMD}$ at the hip fell by $1.7 \%$ for salmeterol patients, whereas it fell by $2.9 \%$ and $3.2 \%$ in the fluticasone and salmeterol/fluticasone groups, respectively. ${ }^{5}$ In contrast, inhaled triamcinolone (not approved for COPD and no longer marketed) was found to lower BMD significantly. 7

A meta-analysis of observational studies found an increased fracture risk among participants with obstructive lung disease, ${ }^{8}$ whereas other trials ${ }^{5}$ and their meta-analysis reported no significant effect. ${ }^{9}$ Thus, the effect of the currently available ICS on the risk of fractures among patients with COPD remains unclear. Our objective was to ascertain systematically the risk of fractures associated with long-term use of ICS compared with control treatments in both trials and real-world studies in patients with COPD. 


\section{METHODS}

\section{Inclusion criteria}

Our inclusion criteria for RCTs were (1) parallel-group RCT of at least 24 weeks duration; (2) participants with COPD of any severity; (3) fluticasone or budesonide (which are licensed for use in COPD) as the intervention versus a control treatment, in which the comparison groups consisted of ICS versus placebo, or ICS in combination with a LABA versus a LABA alone; and (4) outcome data (including zero events) on fracture adverse events.

We also evaluated controlled observational studies (casecontrol, prospective cohort or retrospective cohort) reporting on the risk of fractures with any ICS exposure compared with those without ICS exposure in COPD. Eligible studies had to present ORs, RR/HRs or sufficient data to enable us to calculate the OR.

\section{Exclusion criteria}

We excluded trials of $<24$ weeks duration as we were interested in long-term fracture risk. We also excluded studies evaluating ICS use in acute exacerbations of COPD, or where mixed groups of participants (asthma/COPD) were enrolled but fracture outcomes were not separately reported for each group.

\section{Search strategy}

An electronic search (MEDLINE and EMBASE) was originally carried out in April 2009 as part of an earlier systematic review, ${ }^{10}$ and this search was updated in August 2010 (see the online Appendix 1 for search terms). We examined the websites of the US Food and Drug Administration, and European regulatory authorities, and the manufacturers' clinical trials register of fluticasone $e^{11}$ and budesonide. ${ }^{12}$ The bibliographies of included studies and Cochrane Systematic Reviews were also used to identify relevant articles.

\section{Study selection}

Two reviewers (YKL and RC) independently, and in duplicate, scanned all titles and abstracts that indicated the study was an RCT or observational study evaluating the use of ICS in patients with COPD, and further assessed eligibility after retrieving full text versions of potentially relevant articles.

\section{Study characteristics}

We used a prespecified protocol to record study characteristics, diagnostic criteria for COPD, dose and frequency of interventions, mean age, sex and spirometric data of participants, and previous ICS use. The design and relevant data sources, duration of follow-up, the number of study participants and their selection criteria were recorded for the observational studies.

\section{Risk of bias assessment}

Two reviewers independently assessed the reporting of blinding, allocation concealment, withdrawals and the loss to follow-up in RCTs. In accordance with recommendations on assessing adverse effects, we extracted information on participant selection, ascertainment of exposure and outcomes, and methods of addressing confounding in observational studies. ${ }^{13}$ Publication bias was assessed using a funnel plot.

\section{Data extraction}

Two reviewers independently extracted data (including zero events) on fractures (where available) from trial listings of 'Adverse Events' or 'Serious Adverse Events' in the results summaries from the clinical trials register and regulatory documents. In order to avoid duplication, we extracted fracture data based on unique study identifiers where listed. Unpublished reports were subsequently matched to journal manuscripts based on sample size, duration and intervention arms, and additional data extracted where necessary. Authors were contacted for data clarification where needed. Any discrepancies were resolved with $100 \%$ agreement after rechecking the source papers and further discussion among the three reviewers.

\section{Statistical analysis}

We pooled trial data using Review Manager (RevMan) version 5.1.1 (Nordic Cochrane Center, Copenhagen, Denmark) and calculated the Peto OR, using the recommended approach for meta-analysis of rare adverse events. In situations where the fixed effect model is valid, the Peto OR provides the best $\mathrm{CI}$ coverage and has greater statistical power in analysing rare events as compared with the random effects model. ${ }^{14}{ }^{15} \mathrm{We}$ assessed statistical heterogeneity using the $\mathrm{I}^{2}$ statistic, with $\mathrm{I}^{2}$ $>50 \%$ indicating a substantial level of heterogeneity. ${ }^{16}$ If substantial statistical heterogeneity was found, we planned to explore sources of heterogeneity. Predefined sensitivity analyses were performed to check whether different control comparators and alternative statistical models (fixed effect with no continuity correction using StatsDirect software) would substantially change the findings. ${ }^{14}$ Posthoc sensitivity analyses were performed based on long-term trials of $>12$ months duration, and trials with clear reporting of methodological components such as randomisation, blinding and follow-up.

The number needed to harm (NNH) (and 95\% CI) with ICS was calculated by applying the OR estimates to the control
Figure 1 Flow diagram of the process of article selection for meta-analysis. COPD, chronic obstructive pulmonary disease; ICS, inhaled corticosteroids.
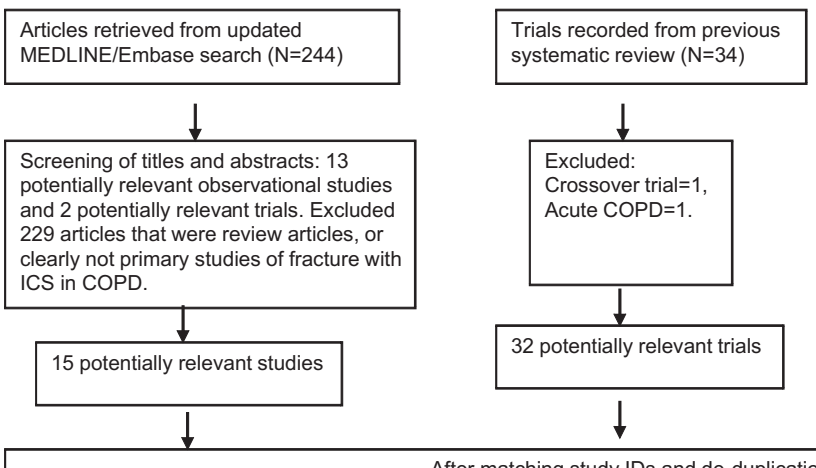

Articles retrieved from GSK study register $(\mathrm{N}=4)$

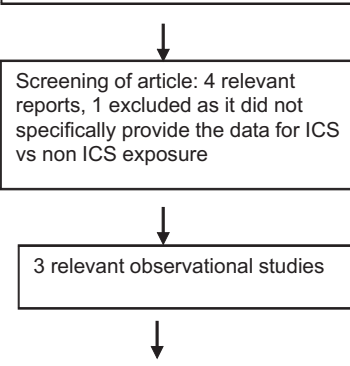

After matching study IDs and de-duplication:

27 eligible trials checked for reports of fracture outcomes: 16 trials with fracture data included in meta-analysis after excluding 11 trials that did not explicitly report on fracture adverse events.

13 eligible observational studies reporting on fracture outcomes: 7 studies included in meta-analysis after excluding 6 studies that had mixed asthma/COPD populations without reporting fracture risk according to group. 
Table 1 Characteristics of randomised controlled trials included in the analysis of fractures

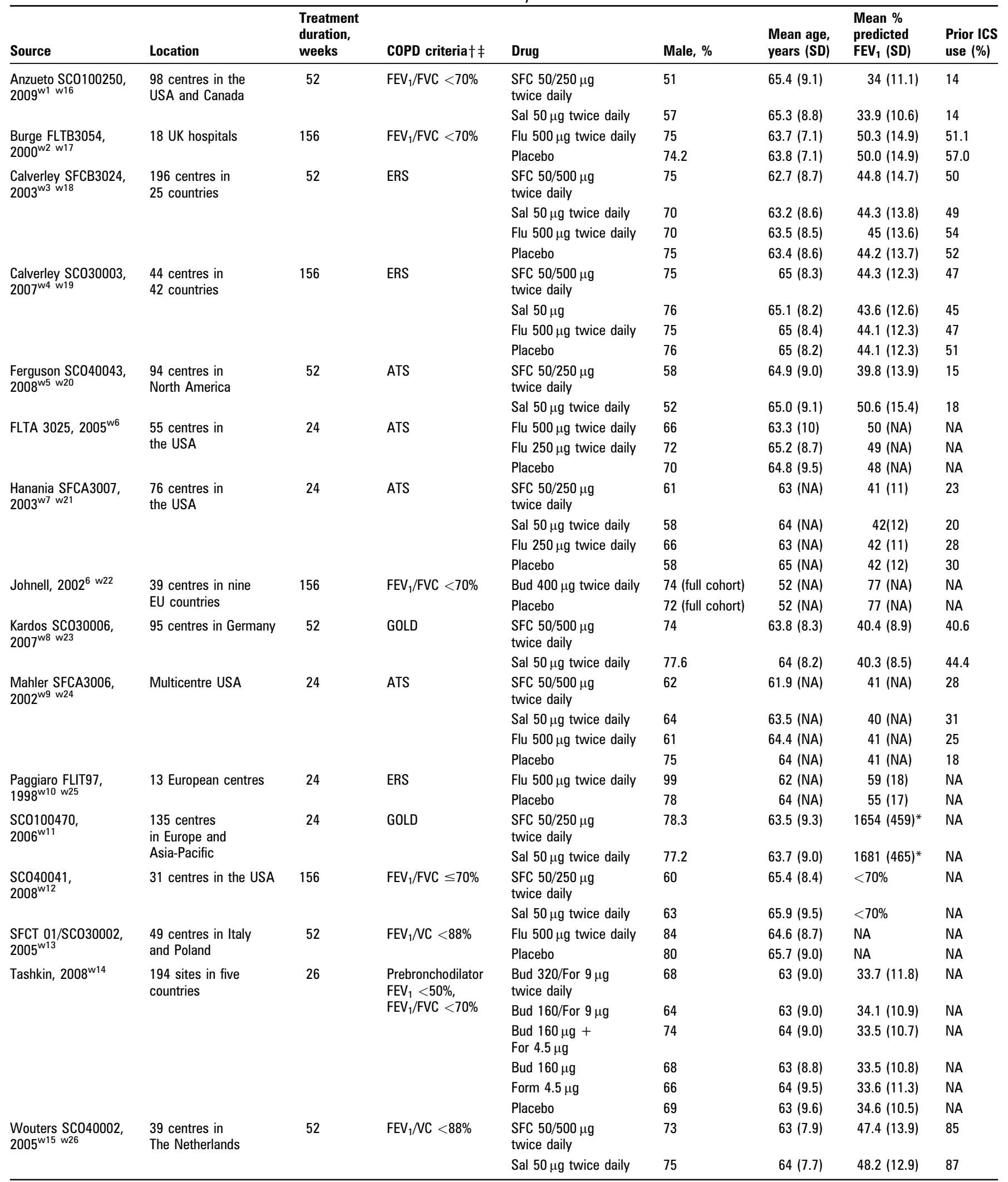

${ }^{*}$ Reported mean $\mathrm{FEV}_{1}$ in millilitres as a percentage of predicted unavailable.

†ATS and GOLD criteria for COPD are $\mathrm{FEV}_{1} / \mathrm{FVC}<70 \%$.

\#ERS criteria for COPD are $\mathrm{FEV}_{1} / \mathrm{VC}<88 \%$ predicted for men and $<89 \%$ predicted for women.

ATS, American Thoracic Society; Bud, budesonide; COPD, chronic obstructive pulmonary disease; ERS, European Respiratory Society; FEV ${ }_{1}$, forced expiratory volume in the first second of expiration; Flu, fluticasone propionate; For, formoterol; FVC, forced vital capacity; GOLD, Global Initiative for Chronic Obstructive Lung Disease; ICS, inhaled corticosteroid; NA, not available; Sal, salmeterol xinafoate; SFC, combination of salmeterol and fluticasone; VC, vital capacity. 
event rate in a large trial population using Visual $\mathrm{Rx}$, version 2.0. ${ }^{17}$ Herein, the NNH is the number of patients who need to be treated with ICS for an additional patient to be harmed by a fracture.

ORs from the observational studies were pooled separately from the RCTs, using the inverse variance, fixed effect model. We assumed similarity between the RR and OR because fractures were rare events. ${ }^{18}$ We prespecified the choice of data for analysis, starting preferentially with: (1) current and/or recent users' versus remote users or non-users; (2) use within the past 6 months -1 year versus remote users or non-users; and (3) any exposure versus non-exposure. To estimate a dose-response trend as log ORs across different exposure levels, we used inverse variance-weighted least squares regression to pool studies that reported dose-specific risk estimates with one referent category. The adjusted OR and their CIs, and the dose of ICS as beclomethasone equivalents in each exposure level, were abstracted. We estimated the median dose for each exposure level when only dose ranges were available. We assumed that open-ended exposure levels would follow the same range pattern as the previous levels. The dose-response analysis was carried out in Stata 10.0.

\section{RESULTS}

The flow chart of study selection is shown in figure 1. A total of 16 RCTs and seven observational studies fulfilled our inclusion criteria for the meta-anaysis.

Table 2 Risk of bias assessment and fracture outcomes in RCTs of inhaled corticosteroids in COPD

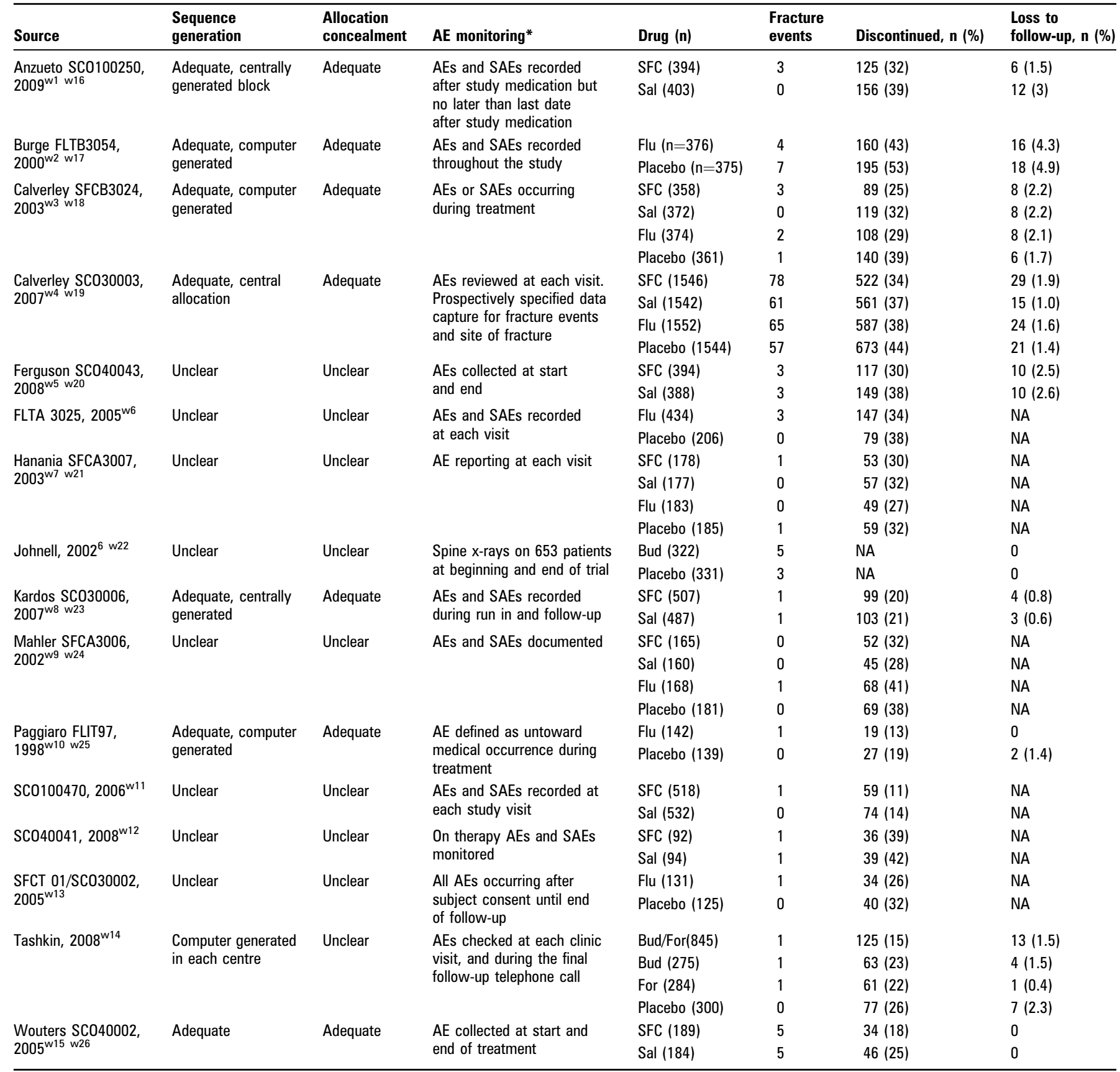

*All RCTs were double-blinded.

$A E$, adverse event; Bud, budesonide; COPD, chronic obstructive pulmonary disease; Flu, fluticasone propionate; For, formoterol; For/Bud, combination of formoterol and budesonide; NA, not available; RCT, randomised controlled trial; SAE, serious adverse event; Sal, salmeterol xinafoate; SFC, combination of salmeterol and fluticasone. 


\section{Randomised controlled trials}

Trial characteristics

Characteristics of the included trials are shown in table 1 . There were a total of 17513 participants with COPD, with 9143 on ICS compared with 8370 controls. The duration of the trials ranged from 24 to 156 weeks, with a mean of 90 weeks across studies. $^{6}{ }^{\text {w1-w15 }}$ (Note that references prefixed with 'w' can be found in the online supplement.)

Inhaled fluticasone was evaluated in 14 trials, while inhaled budesonide was used in two trials. ${ }^{6}$ w14 Trials tended to enrol participants with severe COPD, as the mean forced expiratory volume in $1 \mathrm{~s}\left(\mathrm{FEV}_{1}\right)$ of the participants was $<50 \%$ for nine of the trials. ${ }^{\mathrm{w} 1} \mathrm{w} 3-\mathrm{w} 5 \mathrm{w} 7-9 \mathrm{w} 14 \mathrm{w} 15$ There was a predominance of men ( $>50 \%$ male participants in every trial), with the mean ages typically in the 60-70 year range. Where reported, prior ICS use was noted in $25-50 \%$ of the participants, except for two trials with past ICS exposure for $~ 20 \%$ of patients. $^{\text {w1 }}$ w5
Trial quality was variable (table 2). All the RCTs had blinding of participants and personnel. Discontinuation rates varied from no withdrawals to $53 \%$, with some evidence of differentially higher losses in placebo arms. ${ }^{\mathrm{w} 2}{ }^{\mathrm{w}} 4$ However, many of the patients who discontinued the assigned intervention appeared to remain available for follow-up, as the reported losses only ranged from none to $4.9 \%$. Seven RCTs provided detailed descriptions regarding blinding, adequate sequence generation, allocation concealment and clear reporting of loss

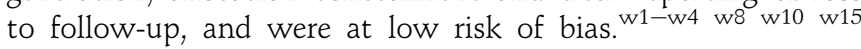
The remaining nine RCTs were at unclear risk of bias owing to lack of clarity in reporting the methods of randomisation. $^{6}$ w5-w7 w9 w11-w14 None of the trials was designed specifically to evaluate fractures, and the data on fractures were extracted from listings of adverse events, except for subsets of participants in two trials where bone outcomes were measured in detail. ${ }^{5}$ Five trials gave details on systemic corticosteroid use for COPD exacerbations, and four of the trials showed
Study or Subgroup

ICS

No ICS

Events Total Events Total Weight Peto, Fixed, 95\% Cl

4.2.1 ICS-LABA vs LABA

Anzueto SCO100250 2009

Calverley SCO30003 2007

Calverley SFCB3024 2003

Ferguson SCO40043 2008

Hanania SFCA3007 2003

Kardos SCO30006 2007

Mahler SFCA3006 2002

SCO100470 2006

SCO400412008

Tashkin 2008

Wouters SCO40002 2005

Subtotal $(95 \% \mathrm{Cl})$

Total events

Heterogeneity: $\chi^{2}=7.54, d f=9(p=0.58) ;\left.\right|^{2}=0 \%$

Test for overall effect: $Z=1.86(p=0.06)$

\subsubsection{ICS alone vs Placebo}

Burge FLTB3054 2000

Calverley SCO30003 2007

Calverley SFCB3024 2003

FLTA3025 2005

Hanania SFCA3007 2003

Johnell 2002

Mahler SFCA3006 2002

Paggiaro FLIT97 1998

SFCT01 2005

Tashkin 2008

Subtotal $(95 \% \mathrm{Cl})$

Total events

$\begin{array}{rr}3 & 394 \\ 78 & 1546 \\ 3 & 358 \\ 3 & 394 \\ 1 & 178 \\ 1 & 507 \\ 0 & 165 \\ 1 & 518 \\ 1 & 92 \\ 1 & 845 \\ 5 & 189 \\ & 5186\end{array}$

\section{$0 \quad 403$}

611542

$0 \quad 372$

$3 \quad 388$

$0 \quad 177$

1487

$0 \quad 160$

$0 \quad 532$

194

1284

$5 \quad 184$ 4623

72

Heterogeneity: $\chi^{2}=7.62, d f=9(p=0.57) ; l^{2}=0 \%$

Test for overall effect: $Z=1.05(p=0.29)$

Total $(95 \% \mathrm{Cl})$

9143

Total events

180

$\begin{array}{rr}4 & 376 \\ 65 & 1552 \\ 2 & 374 \\ 3 & 434 \\ 0 & 183 \\ 5 & 322 \\ 1 & 168 \\ 1 & 142 \\ 1 & 131 \\ 1 & 275 \\ & 3957\end{array}$

$7 \quad 375$

$57 \quad 1544$

1361

0206

1185

$3 \quad 331$

$0 \quad 181$

$0 \quad 139$

$0 \quad 125$

$0 \quad 300$ 3747

69

$3.5 \%$ $38.0 \%$

$1.0 \%$

$0.8 \%$

$0.3 \%$

$2.6 \%$

$0.3 \%$

$0.3 \%$

$0.3 \%$

$0.3 \%$

$47.5 \%$

Heterogeneity: $\chi^{2}=15.43, \mathrm{df}=19(p=0.69) ; l^{2}=0 \%$

Test for overall effect: $Z=2.07(p=0.04)$

Test for subgroup differences: $\chi^{2}=0.28, d f=1(p=0.60), l^{2}=0 \%$
Peto OR Peto OR Peto, Fixed, 95\% Cl

Peto, Fixed, 95\% Cl

$7.60(0.79$ to 73.27$)$

$1.29(0.92$ to 1.81$)$

$7.73(0.80$ to 74.55$)$

0.98 (0.20 to 4.90$)$

7.35 (0.15 to 370.30$)$

0.96 (0.06 to 15.39$)$

Not estimable

7.59 (0.15 to 382.72$)$

$1.02(0.06$ to 16.46$)$

0.27 (0.01 to 6.52$)$

0.97 (0.28 to 3.41$)$

1.34 (0.99 to 1.82$)$

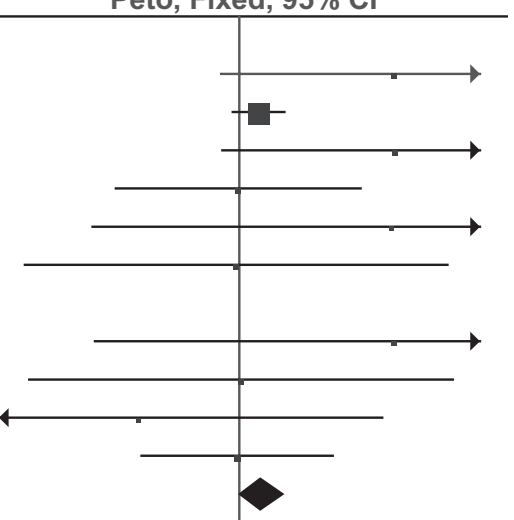

0.57 (0.17 to 1.89$)$

1.14 (0.79 to 1.64$)$

1.88 (0.20 to 18.17$)$

4.39 (0.39 to 49.66$)$

0.14 (0.00 to 6.90$)$

$1.70(0.42$ to 6.87$)$

7.98 (0.16 to 403.44$)$

7.23 (0.14 to 364.68$)$

7.06 ( 0.14 to 356.10$)$

8.09 (0.16 to 409.34$)$

$1.19(0.86$ to 1.64$)$

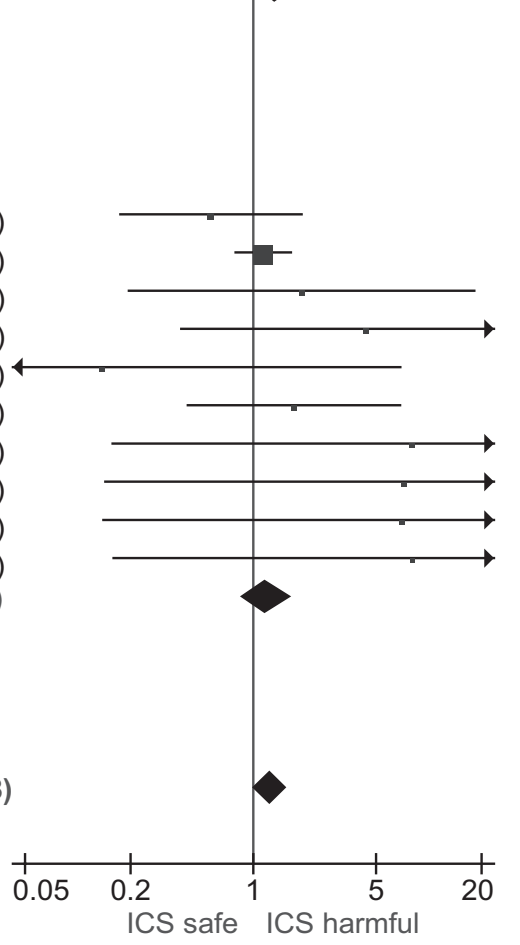

Figure 2 Meta-analysis of odds of fracture with inhaled corticosteroid (ICS) exposure trials of patients with chronic obstructive pulmonary disease. LABA, long-acting $\beta_{2}$-agonist. 
a significantly higher use of oral corticosteroid in the non-ICS intervention arms (online table I).

\section{Main findings}

Across the mean trial duration of 90 weeks, ICS use was associated with a significant increase in the risk of fractures

(180 of $9143(2.0 \%)$ vs 141 of 8370 (1.7\%) for control); Peto OR 1.27 (95\% CI 1.01 to $1.58 ; \mathrm{p}=0.04$ ) (figure 2 ). There was no evidence of statistical heterogeneity among the included trials $\left(\mathrm{I}^{2}=0 \%\right)$.

\section{Sensitivity analysis}

Fixed effect meta-analysis based on the Mantel-Haenszel model (without a continuity correction) yielded similar findings of an increased OR 1.26 (95\% CI 1.01 to $1.59 ; \mathrm{p}=0.04)$ for fractures in RCTs of ICS in COPD.

The pooled Peto OR for seven trials with complete reporting of quality components was 1.23 (95\% CI 0.97 to $1.55),{ }^{\text {w1-w4 } 48}$ w10 w15 as compared with a Peto OR of 1.73 (95\% CI 0.80 to 3.73$)$ for nine trials where some aspects regarding the process of randomisation were not fully reported. ${ }^{6}$ w-w7 w9 w11-w14

Restricting the pooled analysis to four long-term trials (each of 156 weeks duration) 6 w2 w4 w12 yielded a pooled OR of 1.19 (95\% CI 0.94 to 1.51$)$ that is slightly lower than the overall pooled estimate. This may be due to higher quality studies, or change in risk with time. However, the reliability of fracture estimates from long-terms trials such as TORCH is limited by significantly higher oral corticosteroid exposure (online table 1) and withdrawals (with some crossover to ICS treatment) in the placebo arms. ${ }^{19}$

\section{Publication bias}

The funnel plot for fractures appeared to be symmetrical for the RCTs (online figure 1).

\section{Number needed to harm}

The NNH for fractures was estimated at 83 (95\% CI 38 to 2107 ) over the 3 year ICS treatment period in the trial, based on the $5.1 \%$ fracture rates in the salmeterol and placebo arms for the TORCH trial. ${ }^{5}$

\section{Observational studies}

Details of the included studies and the risk of bias are shown in tables 3 and $4{ }^{\text {w27-w33 }}$ There were five nested case-control

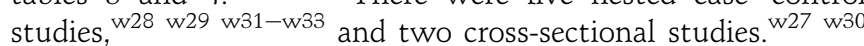
Three of the studies were based in the USA, ${ }^{\mathrm{w} 28-230}$ while the other four were in Europe. ${ }^{\mathrm{w} 27}$ w31-w33 There was a predominance of females in three studies. Fluticasone and/or budesonide were among the ICS evaluated in all the studies, except for one study that evaluated beclomethasone and triamcinolone. ${ }^{\text {w30 }}$ ICS exposure was estimated from dispensing records, and dosages were usually extrapolated from amounts dispensed. Some patients were identified through diagnostic codes for

Table 3 Characteristics of observational studies of inhaled corticosteroids (ICS) and fractures

\begin{tabular}{|c|c|c|c|c|c|}
\hline Study & Design & Fractures & Data source & $\begin{array}{l}\text { COPD definition and } \\
\text { patient characteristics }\end{array}$ & Type of ICS \\
\hline Gonnelli, $2010^{\text {w27 }}$ & Cross-sectional & Vertebral & $\begin{array}{l}57 \text { Italian outpatient } \\
\text { pulmonary centres } \\
\text { January-December } \\
\text { 2005, 3030 eligible } \\
\text { patients }\end{array}$ & $\begin{array}{l}\text { Age }>50 \text { years, referred by } \\
\text { family physicians for COPD, } \\
\mathrm{FEV}_{1} / \mathrm{FVC}<70 \% \text {, with recent } \\
\text { lateral CXR. Mean age } 70 \text { years, } \\
58 \% \text { males }\end{array}$ & BDP, BUD, FP, TRIAM \\
\hline Johannes, $2005^{\mathrm{w} 28}$ & Nested CC & $\begin{array}{l}\text { Non-vertebral mainly } \\
\text { (64\%) upper or lower } \\
\text { limb fractures }\end{array}$ & $\begin{array}{l}\text { United Healthcare } \\
\text { database } 1997-2001 . \\
609 \text { cases } 6323 \text { controls }\end{array}$ & $\begin{array}{l}\text { Adults aged } \geq 40 \text { years with } \\
\text { ICD- } 9 \text { codes for COPD and } \\
\text { asthma (we used data on } \\
\text { patients with COPD only). } \\
\text { Mean age } 52 \text { years, } 30 \% \text { of } \\
\text { cases were male }\end{array}$ & FP, BDP, BUD, FLUNIS, TRIAM \\
\hline Lee, $2004^{\mathrm{w} 29}$ & Nested CC & Non-vertebral & $\begin{array}{l}\text { VA patients; } 1708 \\
\text { cases/6817 controls }\end{array}$ & $\begin{array}{l}\text { New patients with COPD } \\
\text { identified by ICD- } 9 \text { coding. } \\
\text { Mean age } 63 \text { years, } 95 \% \text { male, } \\
\text { with } 1.8 \text { years follow-up }\end{array}$ & TRIAM, BDP, FLUNIS, FP \\
\hline McEvoy, $1998^{\mathrm{w} 30}$ & Cross-sectional & Vertebral & $\begin{array}{l}\text { Minneapolis VA } 176 \\
\text { users/136 non-users }\end{array}$ & $\begin{array}{l}\text { Selection criteria: (1) male } \\
>50 \text { years old; ( }(2) \text { primary } \\
\text { diagnosis COPD; ( } 3 \text { ) FEV } / / F V C \\
\text { ratio } 70 \% \text {; }(4) \text { smoking history } \\
\geq 20 \text { pack-years; and (5) >5 refills } \\
\text { of a } \beta \text {-agonist inhaler within } \\
\text { past year. Mean age } 69 \text { years }\end{array}$ & BDP, TRIAM \\
\hline Pujades-Rodríguez, $2007^{\mathrm{w} 31}$ & Nested CC & Any & $\begin{array}{l}\text { UK Health Improvement } \\
\text { Network database } \\
1998-2005.1235 \\
\text { cases/4598 controls }\end{array}$ & $\begin{array}{l}\text { COPD diagnosis based on general } \\
\text { practice records. Mean age } 69 \text { years, } \\
40 \% \text { males. Mean predicted } \mathrm{FEV}_{1} \\
\text { of } 58 \% \text {. Controls matched by sex } \\
\text { and general practice }\end{array}$ & BDP, FP, BUD \\
\hline $\begin{array}{l}\text { WEUSRTP1127 Miller, } \\
2010^{\text {w32 w34 }}\end{array}$ & $\begin{array}{l}\text { Nested CC Non- } \\
\text { vertebral fracture }\end{array}$ & Non-vertebral & $\begin{array}{l}\text { UK GPRD } 2003-2006, \\
1523 \text { cases/1876 controls }\end{array}$ & $\begin{array}{l}\text { COPD diagnosis on computerised } \\
\text { records. Age } \geq 45 \text { years, } 37 \% \text { male. } \\
\text { Controls matched on age, sex, } \\
\text { general practice and duration in } \\
\text { cohort prior to index date }\end{array}$ & $\begin{array}{l}\text { Primary analysis FP, incomplete } \\
\text { reporting BDP and BUD data }\end{array}$ \\
\hline WWE113669, $2008^{\text {w33 }}$ & Nested CC & Non-vertebral & $\begin{array}{l}\text { UK GPRD 1987-2000, } \\
3105 \text { cases/37 } 801 \\
\text { controls. }\end{array}$ & $\begin{array}{l}\text { COPD diagnosis on computerised } \\
\text { records. Age } 50-85 \text { years, } 66 \% \\
\text { male. Controls matched on age, } \\
\text { sex and general practice }\end{array}$ & FP, BUD, BDP \\
\hline
\end{tabular}

BDP, beclomethasone; BUD, budesonide; CC, case-control; COPD, chronic obstructive pulmonary disease; CXR, chest x-ray; FEV , forced expiratory volume in the first second of expiration; FLUNIS, flunisolide; FP, fluticasone, FVC, forced vital capacity; GPRD, General Practitioner Research Database; ICD, International Classification of Diseases; TRIAM, triamcinolone; VA, Veterans Affairs. 


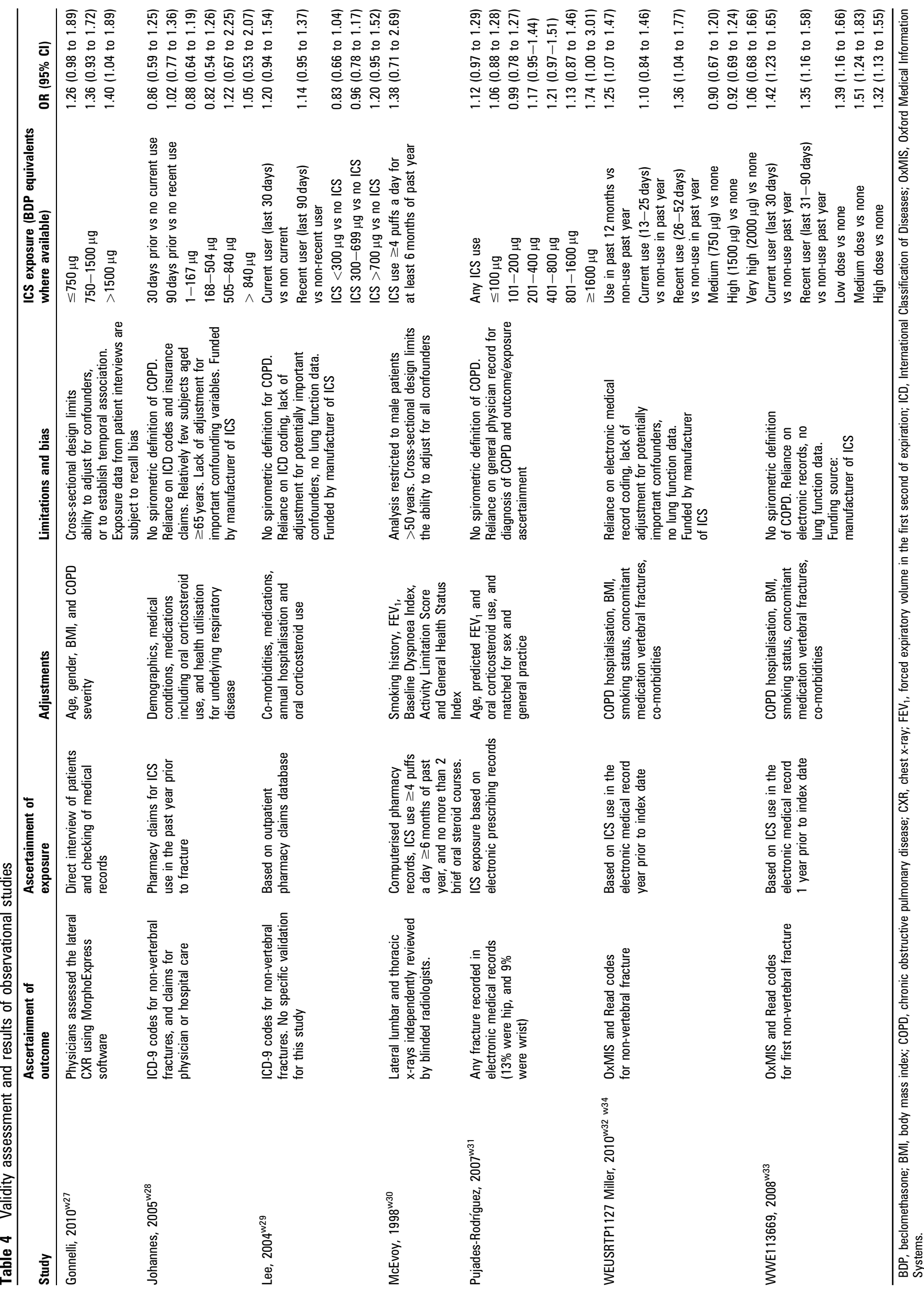

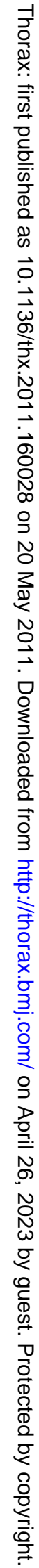


COPD in electronic databases, and the extent of misclassification is unclear. Four studies were funded by manufacturers of ICS. ${ }^{\text {w28 }}$ w29 w32 w33

Findings from the meta-analysis of observational studies according to exposure subcategories are shown in figure 3 . The pooled estimate based on all seven studies, covering current or ever users versus non-users, showed an OR of 1.21 (95\% CI 1.12 to $\left.1.32 ; \mathrm{p}<0.0001, \mathrm{I}^{2}=37 \%\right)$. There were five studies that reported on current users compared with no current exposure which yielded a pooled OR of 1.27 (95\% CI 1.14 to 1.41; $\mathrm{p}<0.0001 ; \mathrm{I}^{2}=48 \%$ ). ${ }^{\text {w28-w30 }}$ w32 w33 Four studies reported on recent users compared with no recent exposure, with very similar findings of a pooled OR of 1.24 (95\% CI 1.12 to 1.37; $\mathrm{p}<0.0001 ; \mathrm{I}^{2}=29 \%$ ). ${ }^{\mathrm{w} 28} \mathrm{w} 29 \mathrm{w} 32 \mathrm{w} 33$

Exclusion of the study that did not enrol fluticasone or budesonide users ${ }^{\mathrm{w} 30}$ did not change the direction or magnitude of the fracture risk for current or ever users (OR 1.21; 95\% CI 1.11 to $1.32 ; \mathrm{p}<0.001)$ in a sensitivity analysis.

One study reported primarily on fluticasone, but provided some data on the category of 'other ICS' exposure involving beclomethasone and budesonide. Meta-analysis based on 'other ICS' category rather than 'fluticasone exposure' yielded a very similar OR of 1.20 (95\% CI 1.11 to 1.29$)$. ${ }^{\text {w32 }}$

\section{Dose-response meta-regression}

Six observational studies were included in this analysis. ${ }^{\text {w27-w29 }}$ w31-w33 Each $500 \mu \mathrm{g}$ increase in beclomethasone dose equivalents was associated with a 9\% increase in the likelihood of fractures, OR 1.09 (95\% CI 1.06 to 1.12; p<0.001) (figure 4).

\section{DISCUSSION}

Our meta-analysis found consistent evidence on the adverse effects of the available long-term ICS (fluticasone and budesonide) treatment on fractures in patients with COPD. We found

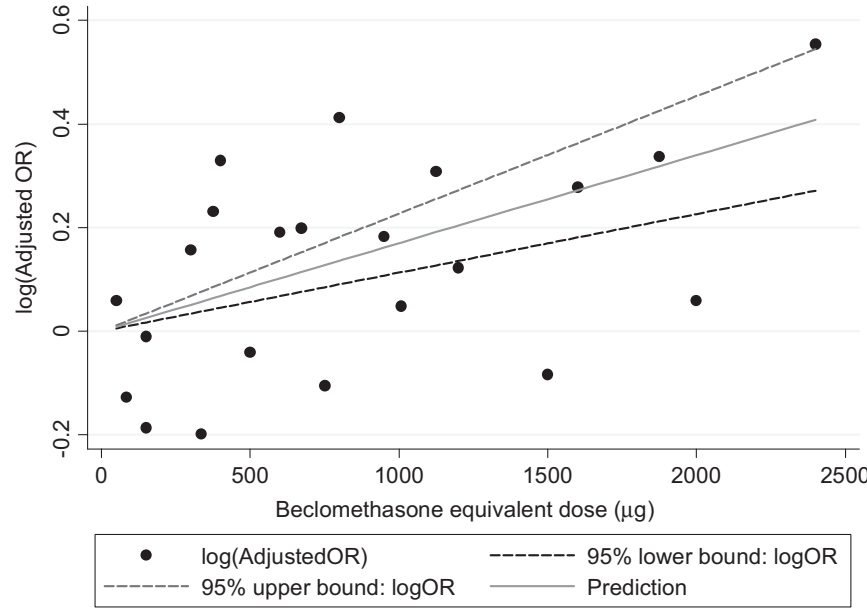

Figure 4 Meta-analysis of inhaled corticosteroids versus controls for fractures in observational studies.

a relative increase of $>20 \%$ in the likelihood of fractures in RCTs and observational studies, Although the pooled estimates from the RCTs are dominated by a single large trial, and the lower bounds of the $95 \%$ CIs lie very close to unity, the totality of the evidence should be considered. Here, the consistency and similarity of the point estimates across study designs, the absence of statistical heterogeneity and the presence of a dose-response effect in the observational studies strengthen the confidence in this association.

\section{Comparisons with previous analysis}

Our consistent findings from trials and observational studies in COPD should be distinguished from previous underpowered meta-analyses limited to published trials, or observational studies which included patients with conditions other than
Figure 3 Meta-analysis of odds of fracture with subcategories of inhaled corticosteroid exposure in observational studies of patients with chronic obstructive pulmonary disease.

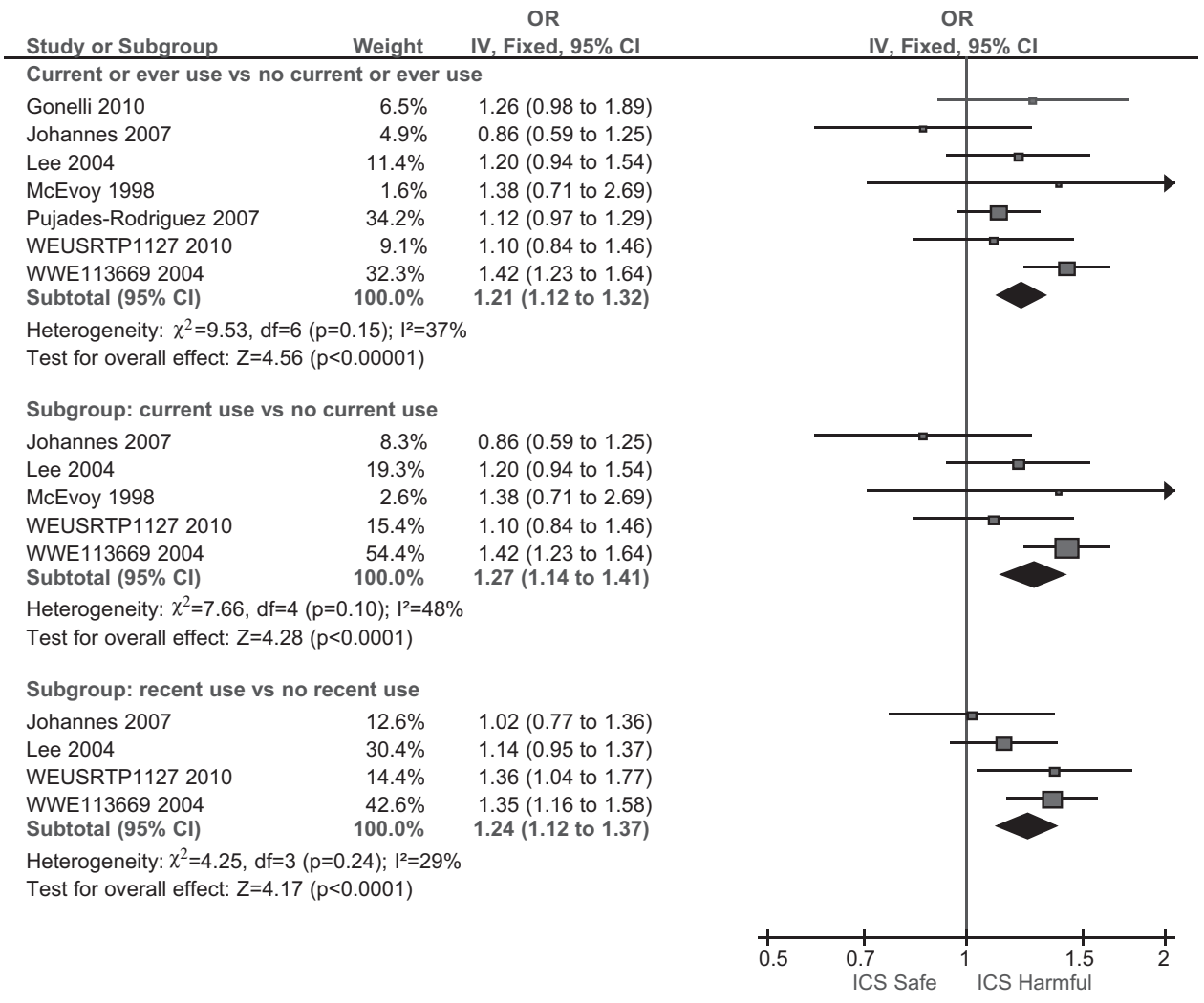


COPD. A meta-analysis of ICS in older adults found no consistent risk based on three COPD trials and several observational studies that enrolled patients who did not have COPD. ${ }^{20}$ Similarly, another meta-analysis reported no increase in fractures based on published data from three long-term trials. ${ }^{9}$ There are also two Cochrane reviews that reported inconclusive findings on the link between ICS and fractures. ${ }^{21} 22$ Another pooled analysis limited to five published case-control studies which included those with other respiratory conditions such as asthma reported a dose-related increased relative fracture risk of $12 \%$ per $1000 \mu \mathrm{g}$ increase in beclomethasone equivalents. ${ }^{8}$ In contrast, our comprehensive meta-analysis of clinical trials included unpublished data with sufficient power to reliably detect a relatively precise estimate of the increase in the likelihood of fractures among 17513 patients with COPD.

The precise mechanisms by which ICS increase the risk of fractures in patients with COPD are uncertain. Patients with COPD are already at high risk from osteoporosis and fractures, which may stem from co-morbidity (eg, susceptibility to falls), nutritional deficiencies, inflammatory markers, and prior corticosteroid exposure. ${ }^{23}$ A small portion of the ICS dose is systemically absorbed and systemic effects are recognised. At large doses, the adverse effects of ICS may come close to that of oral corticosteroids, known to cause increased bone resorption and decreased bone formation in a dose-dependent manner consistent with our dose-response analysis. ${ }^{24}$

\section{Limitations}

The lower limit of the $95 \%$ CI for fracture risk from RCT data is close to the threshold of the null effect, thus introducing an element of uncertainty. Moreover, the trial data originate mainly from unpublished, non-peer-reviewed company reports. Absence of information in RCTs regarding timing of fracture in relation to ICS use also precludes meta-regression of fracture risk according to exposure duration. Most of the RCTs did not use specific methods to define and record fractures, and it is possible that misclassification or underascertainment occurred, although this should not have a differential effect in a double-blind study. Many trial participants had previous ICS exposure prior to joining the trial, and we noted differential oral corticosteroid exposure in control arms (online table 1), thus attenuating observable differences between groups. ${ }^{19}$ While risk estimates from observational data were adjusted for concomitant medications, this was not so for the RCTs, and the extent of bisphosphonate use may affect the fracture risk. ${ }^{5}$

Data on budesonide are available from only two trials, ${ }^{6}$ and there are no head to head long-term trials of fluticasone versus budesonide in COPD. We did not specifically evaluate trials of flunisolide, triamcinolone or mometasone as they are not licensed for COPD. Most trial participants were male, and studies were based on older ICS devices, limiting applicability. Observational studies are susceptible to residual confounding.

\section{Future research}

Future studies should evaluate the precise location of the fractures (peripheral vs central, traumatic vs non-traumatic), and whether the risk varies by COPD severity. Studies should attempt to determine whether concomitant bone-protective drugs can ameliorate this risk of fractures associated with ICS, and should recruit a larger proportion of postmenopausal women. The risk of fractures associated with the newer formulations of ICS needs to be assessed. The dose-response relationships for efficacy and safety need detailed evaluation so that the lowest effective dose can be prescribed.

\section{Implications for clinical practice}

The relative increase of $\sim 27 \%$ in fracture risk should be weighted against the $20-25 \%$ relative reduction of COPD exacerbations, with a potential number needed to treat of 6 per year in preventing exacerbations. ${ }^{4}$ This contrasts with the fracture $\mathrm{NNH}$ of 83 over a 3 -year period in the same trial population. Thus, the benefit/harm ratio may be less of a concern for patients with low underlying fracture risk but who have more severe COPD and are experiencing frequent exacerbations. However, as cumulative ICS exposure may be hazardous in older patients with multiple co-morbidities and low BMD, ICS treatment needs more careful consideration, and bone-protective drugs may be warranted.

\section{Conclusions}

Our findings suggest a dose-dependent increased risk of fractures associated with the long-term use of inhaled fluticasone or budesonide in patients with COPD. Clinicians should carefully consider the modest risk of fractures associated with ICS treatment, along with their adverse effects on other outcomes and balance this against the symptomatic benefits in reducing exacerbations.

Funding SS is supported by the Johns Hopkins Clinical Research Scholars Program. This publication was made possible by Grant Number 1KL2RR025006-03 from the National Center for Research Resources (NCRR), a component of the National Institutes of Health (NIH), and NIH Roadmap for Medical Research. Its contents are solely the responsibility of the authors and do not necessarily represent the official view of the NCRR or NIH. Information on the NCRR is available at http://www.ncrr.nih gov/. Information on Re-engineering the Clinical Research Enterprise can be obtained from http://nihroadmap.nih.gov/clinicalresearch/overview-translational.asp.

\section{Competing interests None.}

Contributors YKL and SS conceptualised the review and drew up the protocol. YKL, SS and RC were involved in study selection and data extraction. YKL and RC performed the data analysis. YKL, RC and SS drafted and revised the manuscript.

Provenance and peer review Not commissioned; externally peer reviewed.

\section{REFERENCES}

1. Suissa S, McGhan R, Niewoehner D, et al. Inhaled corticosteroids in chronic obstructive pulmonary disease. Proc Am Thorac Soc 2007:4:535-42.

2. Global Initiative for Chronic Obstructive Lung-Disease (GOLD). Global Strategy for the Diagnosis, Management and Prevention of COPD. http://www.goldcopd.org (accessed 9 Dec 2010).

3. Singh S, Amin AV, Loke YK. Long-term use of inhaled corticosteroids and the risk of pneumonia in chronic obstructive pulmonary disease: a meta-analysis. Arch Intern Med 2009;169:219-29.

4. Singh S, Loke YK. An overview of the benefits and drawbacks of inhaled corticosteroids in chronic obstructive pulmonary disease. Int J Chron Obstruct Pulmon Dis 2010;5:189-95.

5. Ferguson GT, Calverley PMA, Anderson JA, et al. Prevalence and progression of osteoporosis in patients with COPD: results from the TOwards a Revolution in COPD Health study. Chest 2009;136:1456-65.

6. Johnell 0, Pauwels R, Lofdahl CG, et al. Bone mineral density in patients with chronic obstructive pulmonary disease treated with budesonide Turbuhaler. Eur Respir J 2002;19:1058-63.

7. Scanlon PD, Connett JE, Wise RA, et al. Loss of bone density with inhaled triamcinolone in Lung Health Study II. Am J Respir Crit Care Med 2004;170:1302-9.

8. Weatherall M, James K, Clay J, et al. Dose-response relationship for risk of nonvertebral fracture with inhaled corticosteroids. Clin Exp Allergy 2008;38:1451-8.

9. Drummond MB, Dasenbrook EC, Pitz MW, et al. Inhaled corticosteroids in patients with stable chronic obstructive pulmonary disease: a systematic review and meta-analysis. JAMA 2008;300:2407-16.

10. Loke YK, Kwok CS, Singh S. Risk of myocardial infarction and cardiovascular death associated with inhaled corticosteroids in COPD. Eur Respir J 2010;35:1003-21.

11. GlaxoSmithKline. GlaxoSmithKline Clinical Trials Register. http://www.gskclinicalstudyregister.com/.

12. AstraZeneca. Astra Zeneca Clinical Trials Register. http://www astrazenecaclinicaltrials.com/.

13. Loke YK, Price D, Herxheimer A. Chapter 14: Adverse effects. In: Higgins JPT, Green S eds. Cochrane Handbook for Systematic Reviews of Interventions. Chichester (UK): John Wiley \& Sons, 2008:442-4.

14. Bradburn MJ, Deeks JJ, Berlin JA, et al. Much ado about nothing: a comparison of the performance of meta-analytical methods with rare events. Stat Med 2007;26:53-77. 
15. Higgins JPT, Deeks JJ, Altman DG. Chapter 16. Special topics in statistics. In: Higgins JPT, Green S, eds. Cochrane Handbook for Systematic Reviews of Interventions. Chichester (UK): John Wiley \& Sons, 2008:520-4.

16. Higgins JP, Thompson SG, Deeks JJ, et al. Measuring inconsistency in metaanalyses. BMJ 2003;327:557-60.

17. Cates CJ. Dr Chris Cates' EBM Web site. http://www.nntonline.net laccessed 9 Dec 2010)

18. Davies HT, Crombie IK, Tavakoli M. When can odds ratios mislead? BMJ 1998:316:989-91.

19. Vestbo J, Anderson JA, Calverley PM, et al. Bias due to withdrawal in long-term randomised trials in COPD: evidence from the TORCH study. Clin Respir J 2011;5:44-9.
20. Etminan M, Sadatsafavi M, Ganjizadeh Zavareh S, et al. Inhaled corticosteroids and the risk of fractures in older adults: a systematic review and meta-analysis. Drug Saf 2008;31:409-14.

21. Jones A, Fay JK, Burr M, et al. Inhaled corticosteroid effects on bone metabolism in asthma and mild chronic obstructive pulmonary disease. Cochrane Database Syst Rev 2002;(1):CD003537.

22. Yang IA, Fong KM, Sim EH, et al. Inhaled corticosteroids for stable chronic obstructive pulmonary disease. Cochrane Database Syst Rev 2007;(2):CD002991.

23. Langhammer A, Forsmo $\mathrm{S}$, Syversen U Long-term therapy in COPD: any evidence of adverse effect on bone? Int J Chron Obstruct Pulmon Dis 2009;4:365-80.

24. van Staa TP, Leufkens HG, Cooper C. The epidemiology of corticosteroid-induced osteoporosis: a meta-analysis. Osteoporos Int 2002:13:777-87.

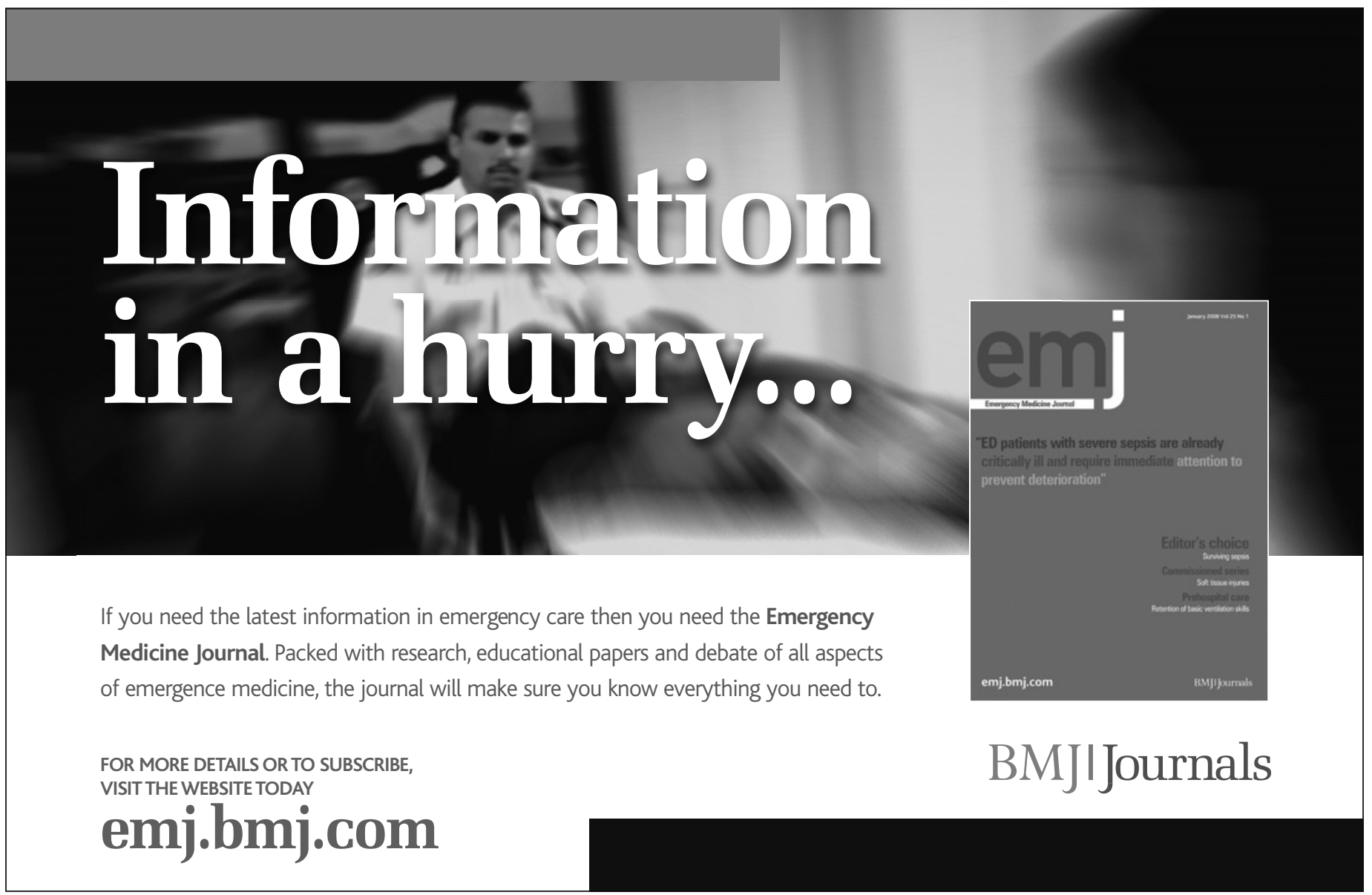

